\title{
Conservative Treatment Approach in Primary Spontaneous Pneumothorax
}

\author{
Cenk Balta and Mustafa Kuzucuoglu \\ Department of Thoracic Surgey, Balikesir University, Faculty of Medicine, Cagis Kampusu, Balikesir, Turkey
}

\begin{abstract}
Objective: To evaluate the efficacy and pain levels of minimally invasive approaches in the treatment of primary spontaneous pneumothorax (PSP).

Study Design: Observational study

Place and Duration of Study: Department of Thoracic Surgery, Balikesir University, Turkey, from August 2017 to August 2019.

Methodology: Patients with primary spontaneous pneumothorax aged over 18 years, hospitalised in the thoracic surgery department, and treated with conservative and minimally invasive approaches were included in the study. These approaches included continuous oxygen inhalation and small bore thorax catheter drainage. Patients were evaluated for age, gender, pneumothorax level, treatment modality, duration of discharge and recurrence. The obtained data were analysed statistically.

Results: A total of 80 patients (76 males, 4 females) had a mean age of $28.8 \pm 9.47$ years. While $24(30 \%)$ of the patients were treated conservatively, 56 patients $(70 \%)$ underwent drainage with $8 \mathrm{~F}$ thorax catheter. Two patients who had conservative treatment primarily, later underwent drainage with an $8 \mathrm{~F}$ thorax catheter due to the lack of response to treatment. One patient underwent videothoraco-scopic bulla excision and partial parietal pleurectomy because of the nonexpandable lung. The average length of hospital stay was $3.55 \pm 1.41$ days.

Conclusion: Conservative treatment and treatment with small catheters are effective approaches in spontaneous pneumothorax patients. Patients with PSP should be managed first with minimally invasive approaches.
\end{abstract}

Key Words: Pneumothorax, Primary spontaneous pneumothorax, Conservative treatment, Small size catheters.

How to cite this article: Balta C, Kuzucuoglu M. Conservative treatment approach in primary spontaneous pneumothorax. J Coll Physicians Surg Pak 2020; 30(2):168-171.

\section{INTRODUCTION}

Primary spontaneous pneumothorax (PSP) is seen at a rate of $18-28 / 100,000$ in men and 1.2-6/100,000 in women; and constitutes $20 \%$ of hospitalisations in thoracic surgery clinics.1,2 PSP is often seen in slim young male smokers, and the etiology is still unclear. However, rupture of bullae and blebs are known to be mainly responsible in the etiology. Accumulation of neutrophils and macrophages due to distal airway inflammation, protease-antiprotease imbalance and disruption of elastic fibers result in bullae and bleb formation. When a bleb ruptures, air from the alveoli escapes to the peural space, causing PSP. 3,4

Patients typically apply to the hospital with sudden onset of chest pain and respiratory distress. While physical examination and lung X-ray are sufficient for diagnosis,

Correspondence to: Dr. Mustafa Kuzucuoglu, Department of Thoracic Surgery, Faculty of Medicine, Balikesir University, Cagis Kampusu, Balikesir, Turkey

E-mail: mustafakuzucuoglu@hotmail.com

Received: October 28, 2019; Revised: January 20, 2020;

Accepted: January 27, 2020 thorax computed tomography (CT) is the most effective imaging method in the diagnosis of pneumothorax. There is no consensus regarding the initial treatment of PSP. Tube thoracostomy and closed underwater drainage is the traditional initial treatment option. ${ }^{5-7}$ The novel surgical procedures in thoracic surgery interest towards minimally invasive techniques, since they result in reduced postoperative pain and better cosmetic results. ${ }^{8}$

The traditional method seems to be effective and have many advantages; however, there is no scientific evidence supporting the superiority of this method than the minimal invasive approaches.

Thus, the aim of this study was to evaluate the treatment response in patients who were admitted to the clinic with a diagnosis of PSP for the first time and treated with conservative and/or minimally invasive methods.

\section{METHODOLOGY}

This observational study included patients who were admitted to Balikesir University Thoracic Surgery Department, Hospital, from August 2017 to August 2019 with PSP. Patients under 18 years of age, had a history of thoracic disease or previous history of pneumothorax 
were excluded. Patients were evaluated in terms of age, gender, pneumothorax level, treatment method, duration of discharge, and recurrence rate.

Pneumothorax levels of the patients were calculated with light index, ${ }^{9}$ and were defined as minimal pneumothorax below $20 \%$, partial pneumothorax between $20-40 \%$, subtotal pneumothorax between $40-60 \%$, and total pneumothorax above $60 \%$.

Clinically, patients with respiratory rate less than $24 / \mathrm{min}$, pulse rate between $60-120 / \mathrm{min}$, normal non-invasive arterial blood pressure, $>90 \%$ non-invasive oxygen saturation $\left(\mathrm{SPO}_{2}\right)$ in room air, and absence of dyspnea are considered as stable.5,6 Medical treatment was the first treatment choice for patients who are considered stable; bronchodilator nebuliser inhalation (Ipratropium bromide and salbutamol), nonsteroidal anti-inflammatory drugs (NSAIDs) with analgesic and continuous nasal $4 \mathrm{~L} / \mathrm{min}$ of oxygen inhalation were administered. In unstable patients, drainage and negative aspiration were performed with $8 \mathrm{~F}$ pleural drainage catheter in addition to medical treatment performed in stable patients as the first treatment choice (Figure 1). The treatment responses of the patients were evaluated by chest $\mathrm{X}$-rays.

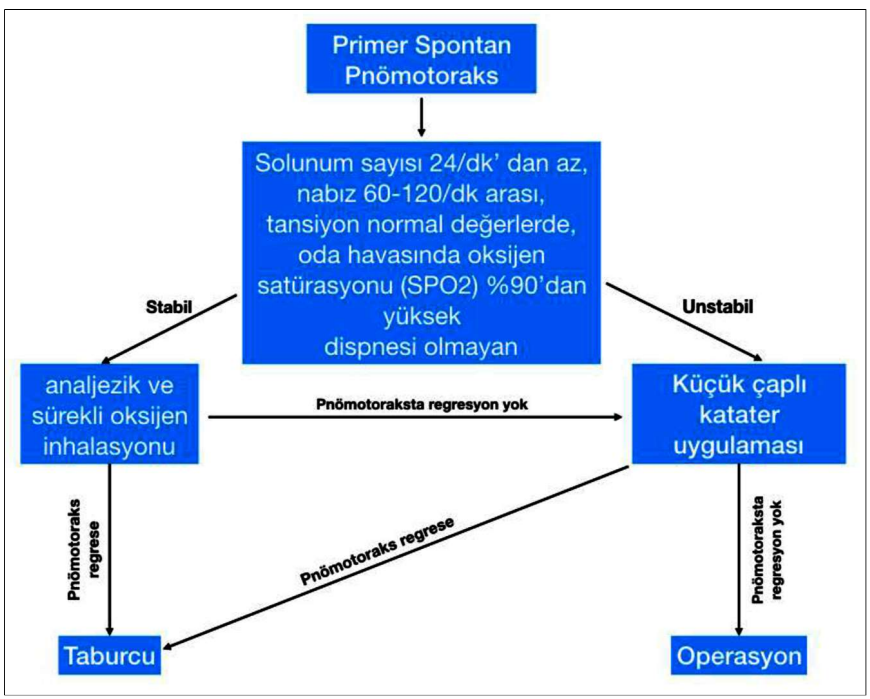

Figure 1: Primary spontaneous pneumothorax treatment algorithm.

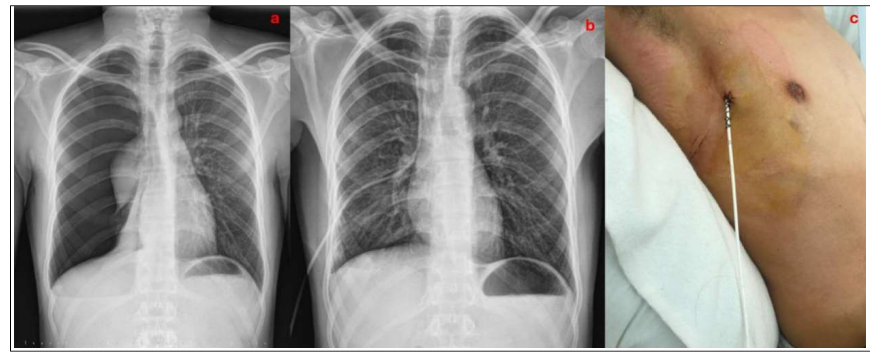

Figure 2: A patient with a primary spontaneous pneumothorax who was accepted as unstable, and underwent drainage with $8 \mathrm{~F}$ catheter: a) right total pneumothorax on lung X-ray at admission, b) appearance of the expanding lung and thoracic catheter on lung X-ray after treatment, c) appearance of $8 \mathrm{~F}$ thorax catheter.
The obtained data were statistically evaluated with the SPSS (Statistical Package for the Social Sciences version 24.0; SPSS Inc., Chicago, IL, USA) programme. The normal distribution assumption of the data was checked by Kolmogorov-Smirnov test. Descriptive statistics of the data were made. In all statistical analyses, those with $p$-values less than 0.05 were considered significant. The relationship between the nominal data was examined by multi-chamber tables and Chi-square test. $\mathrm{OR} \pm 95 \% \mathrm{Cl}$ was calculated.

For this study, approval was taken from Balikesir University Faculty of Medicine Clinical Research Ethics Committee (Decision No: 219/127). This study was conducted in accordance with the principles of the Helsinki Declaration (Version: B.10.4.ISM.4.06.68.48/184).

\section{RESULTS}

The mean age of 76 men (95\%) and 4 women (5\%) included in the study was $28.88 \pm 9.47$ years. Pneumothorax was detected on the right side in 42 patients $(52.5 \%)$ and pneumothorax was detected on the left side in 38 patients $(47.5 \%)$. According to light index, 14 patients were accepted as minimal (17.5\%), 10 patients as partial $(12.5 \%)$, eight patients as subtotal $(10 \%)$, and 48 patients as total pneumothorax $(60 \%)$. Sixty-five patients included in the study were smokers $(81.25 \%)$.

Of the patients included in the study, clinically stable 24 patients $(30 \%)$ were treated with medical therapy alone; whereas, 56 patients $(70 \%)$, who were considered unstable, treated with drainage and negative aspiration with $8 \mathrm{~F}$ pleural drainage catheter (Figure 2). When the relationship between the patients' degree of pneumothorax and conservative treatment was examined by Chi-square analysis, a statistically significant difference was found between the groups $(p=0.001$, Table I). However, when the patients with subtotal and total pneumothorax were evaluated as one group, it was seen these patients required 53 times more surgery than the other patients (OR: $53.667 ; 95 \% \mathrm{Cl}: 7.68-375.01$ ).

Two patients who were accepted as stable were treated with $8 \mathrm{~F}$ catheter drainage because of no radiological recovery within 72 hours despite treatment. The mean length of hospitalisation of patients, who were stable and conservatively treated, was calculated as $3.33 \pm 1.34$ days. A 52-year-old male patient, who was accepted as unstable and underwent drainage with $8 \mathrm{~F}$ catheter at the time of hospitalization, underwent videothoracoscopic surgery (VATS) bulla excision and partial parietal

Table I: Pneumothorax degrees and treatment approaches.

\begin{tabular}{lcccc}
\hline & Conservative & $\begin{array}{c}\text { Catheter } \\
\text { thoracostomy }\end{array}$ & Total & p-value \\
\hline Minimal & 14 & 0 & 14 & $0.001^{*}$ \\
Partial & 9 & 1 & 10 & \\
Subtotal & 1 & 7 & 8 & \\
\hline Total & 0 & 48 & 48 & \\
\hline
\end{tabular}

${ }^{*}$ Fisher's exact test. 
pleurectomy on the 5th day because of continuing air leakage. Mean duration of hospitalisation of unstable patients was $3.64 \pm 1.44$ days. The average length of hospital stay was $3.55 \pm 1.41$ days in all patients.

Two patients $(2.5 \%)$ who were accepted as unstable and treated with $8 \mathrm{~F}$ catheter, admitted with recurrent pneumothorax 2 weeks and 3 months after discharge, respectively. Patients underwent bulla excision with VATS and partial parietal pleurectomy. No other patient had a recurrence.

\section{DISCUSSION}

In the American College of Chest Physicians (ACCP) guidelines, 5 clinical stability was defined as the respiratory rate less than 24 / minutes, pulse between 60-120 / min, blood pressure at normal values and in room air oxygen saturation $\left(\mathrm{SPO}_{2}\right)$ higher than $90 \%$. The British Thoracic Society (BTS) guideline ${ }^{8}$ added "should not have dyspnea" to the definition. ${ }^{6}$ Those who did not meet one or more of these criteria were considered clinically unstable. Based on the guidelines, the authors primarily applied a conservative approach in their clinical practice, with medical treatment in stable patients, and drainage with an $8 \mathrm{~F}$ pleural drainage catheter in unstable patients.

The initial treatment of PSP should include improvement of symptoms. The severity of symptoms may not depend on the degree of pneumothorax. It is related with lung reserves. ${ }^{6}$ There are multiple rating criteria for the degree of pneumothorax in the guidelines. 7,8,9 However, all of the described ratings have been made by direct chest X-ray and it is more valuable to perform volumetric measurements by thorax CT.6,10 In thus study, the degree of pneumothorax was determined on chest X-ray using light criteria.

The pneumothorax guidelines, published by the chest diseases communities in recent years, ${ }^{5-7}$ recommend conservative approach for the treatment of minimal pneumothorax and drainage for large pneumothorax. However, in a study published by Northfield, ${ }^{11}$ the risk of tension pneumothorax is reported higher in the patients with minimal pneumothorax and respiratory distress.

In the study by O'Rourke et al.,12 forty asymptomatic patients of one hundred and thirty PSP patients were treated with conservative approach. The degree of pneumothorax were between $5-50 \%$, and $80 \%$ of patients had less than $15 \%$ pneumothorax. Nine of these patients had required surgical treatment during follow-up. Studies have shown that pleural-free air might be absorbed up to $1.25-1.80 \%$ of hemithorax volume in 24 hours. This rate can reach up to 3 - $4 \%$ with oxygen support. As mentioned in recent articles, conservative treatment is an effective treatment option in minimal and non-symptomatic PSP cases. ${ }^{13,14}$ Despite those guidelines, thoracic surgeons from several centres prefer tube thoracostomy instead of small bore catheters. ${ }^{15,16}$ In this study, the authors pre- ferred conservative treatment in 24 non-symptomatic patients and only 2 patients required surgical treatment during follow-up.

Needle aspiration, small or large bore catheters are used in the treatment of pneumothorax and no significant difference was found between procedure success. ${ }^{17,18}$ In addition, Terzi et al. evaluated small and large diameter thoracic catheters in terms of pain and stated that small diameter thoracic catheter caused less pain. ${ }^{19}$ Although the authors did not evaluate patients treated with large thoracic catheters in this study, it was observed that the conservative approach and treatment with small catheters were sufficient for treatment and were more comfortable for patients.

The first limitation of this study was a relatively small sample size. Secondly, since the design of the study did not allow a control group with a large bore catheter insertion, the authors were not able to show the comparative data between two techniques. Another limitation was the use of chest X-ray instead of CT scan, which was due to the use of light Index.

\section{CONCLUSION}

The main aim of treating pneumothorax is to relieve respiratory distress and chest pain. Conservative treatment can be performed in patients with stable vital signs and without dyspnea. In unstable patients, removal of the air from the pleural space and expansion of the lung is mandatory. The effectiveness of small bore thoracic catheters is similar to the large bore thorax drains. Pain, infection rate, and cosmetic results of small bore thorax catheters have more favourable results.

\section{ETHICAL APPROVAL:}

Ethical approval from Institutional Review Board (IRB) of Balikesir University Faculty of Medicine was obtained prior to initiation of the research work

\section{PATIENTS' CONSENT:}

Informed consents were obtained from all participants to publish the data concerning this case

\section{CONFLICT OF INTEREST:}

Authors declared no conflict of interest.

\section{AUTHORS' CONTRIBUTION:}

CB: Conception and design of the work, and the acquisition, analysis, and interpretation of the data for the work and agreement to be accountable for all aspects of the work in ensuring that questions related to the accuracy or integrity of any part of the work were appro-priately investigated and resolved; final approval of the version to be published; drafting the work; designing of the work; Interpretation of data for the work.

MK: Drafting the work or revising it critically for important intellectual content; Designing of the work; interpretation of data for the work. 


\section{REFERENCES}

1. Melton LJ, Hepper NG, Offord KP. Incidence of spontaneous pneumothorax in olmsted county, minnesota: 1950 to 1974. Am Rev Respir Dis 1979; 120:1379-82.

2. Rivas de Andres JJ, Jimenez Lopez MF, Molins Lopez-Rodo L, Perez Trullen A, Torres Lanza J. Normativa sobre el diagnostico y el tratamiento del pneumotorax. Arch Bronconeumol 2008; 44:437-48.

3. Sahn SA, Heffner JE. Spontaneous pneumothorax. $N$ Eng $J$ Med 2000; 342:868-74.

4. Donahue DM, Wright CD, Viale G, Mathisen DJ. Resection of pulmonary blebs and pleu-rodesis for spontaneous pneumothorax. Chest 1993; 104:1767-9.

5. Baumann MH, Strange C, Heffner JE, Light R, Kirby TJ, Klein J, et al. Aacp pneumothorax consensus group. Management of spontaneous pneumothorax: An American college of chest physicians delphi consensus statement. Chest 2001; 119:590-602.

6. MacDuff A, Arnold A, Harvey J. BTS pleural disease guideline group. Management of spontaneous pneumothorax: British thoracic society pleural disease guideline 2010. Thorax 2010; 65:18-31.

7. De Leyn P, Lismonde M, Niname V, Noopen M, Slabbynck H, van Meerhaeghe A, et al. Guidelines Belgian society of pneumology. belgian society of pneumology: Guidelines on the management of spontaneous pneumothorax. Acta Chir Belg 2005; 105:265-7.

8. Cho S, Lee EB. Management of primary and secondary pneumothorax using a small-bore thoracic catheter. Interact Cardiovasc Thorac Surg 2010; 11:146-9.

9. Light RW, ed. Pleural Diseases. Dis Mon 1992; 38:266-331.

10. Kelly AM, Loy J, Tsang AYL, Graham CA. Estimating the rate of re-expansion of sponta-neous pneumothorax by a formula derived from computed tomography volumetry studies. Emerg Med J 2006; 23:780-2.

11. Northfield TC. Oxygen therapy for spontaneous pneumothorax. BMJ 1971; 4:86-8.

12. O'Rourke JP, Yee ES. Civilian spontaneous pneumothorax: Treatment options and long term results. Chest 1989; 96:1302-6.

13. Bintcliffe OJ, Hallifax RJ, Edey A, Feller-Kopman D, Lee YC, Marquette $\mathrm{CH}$, et al. Spontaneous pneumothorax: Time to rethink management? Lancet Respir Med 2015; 3:578-88.

14. Aguinagalde B, Aranda JL, Busca P, Martinez I, Royo I, Zabaleta $\mathrm{J}$, et al. SECT clinical practice guideline on the management of patients with spontaneous pneumothorax. Cir Esp 2018; 96:3-11.

15. Stolz A, Harustiak T, Pafko P. Spontaneous pneumothorax management. Eur Surg 2008; 40:187-92.

16. Kuester JR, Frese S, Stein RM, Roth T, Beshay M, Schmid RA. Treatment of primary spontaneous pneumothorax in Switzerland: Results of a survey. Int Cardi Thor Surg 2006; 5:139-44.

17. Kim IH, Kang DK, Min HK, Hwang YH. A prospective randomized trial comparing manual needle aspiration to closed thoracostomy as an initial treatment for the first episode of primary spontaneous pneumothorax. Korean J Thorac Cardiovasc Surg 2019; 52:85-90.

18. Kaneda H, Nakano T, Taniguchi $\mathrm{Y}$, Saito T, Konobu T, Saito $\mathrm{Y}$. Three-step management of pneumothorax: time for a re-think on initial management. Interact Cardiovasc Thorac Surg 2013; 16:186-92.

19. Terzi A, Feil B, Bonadiman C, Lonardoni A, Spilimbergo I, Pergher $\mathrm{S}$, et al. The use of flexible spiral drains after noncardiac thoracic surgery. Eur J Cardiothorac Surg 2005; 27: 134-7. 